\title{
“DOUBLE CODING” IN THE HISTORY OF ART
}

\section{Afonina O. S.}

\section{INTRODUCTION}

In the history of art, cultural code, as the well-established system of certain signs and symbols, has always acquired new meanings in the intellectual games of the authors. The formation of a system of codes in the texts of culture and the birth of an integral sign-semantic structure in the signification procedures determines the genesis of coding, which is complemented by artistic techniques of "double coding" - quotes, allusions, reminiscences, connotations and contaminations of archetypal codes. Cultural code in the art of the XX - early XXI century gets additional opportunities for open dialogue or intertextuality, expansion of the intonation dictionary of the epoch or its collapse.

"Double coding" in art is based on the definitions of the famous American architect and postmodern theorist Charles Jenks, among which are "playing with semantics and metaphoricality", "radical eclecticism", "various means of semiotic coding”, "paradoxical dualism". The definitions of Jean-François Lyotard "language game", "absurdism", "pluralism of forms and meanings" have something in common with them. There are also special works on psychology devoted to problems related to the theory of "double coding". It turned out that these definitions are applicable to the analysis of works of art in the history of art, and not only in the art of postmodernism. Of course, here "double coding" is close to the analysis of interpretation.

The purpose of the article is to highlight the codes of culture and the methods of "double coding" in works of art from different historical periods. The work methodology is based on the use of comparison methods; generalizations for the conceptualization and expansion of the meaning of "cultural codes" and "double coding" in art. The scientific novelty of the work lies in the actualization of the questions of "double coding" in art as a process of finding new meanings and forms of works.

\section{Theoretical foundations of the study of culture codes and "double coding" in art in the scientific literature}

Works of modern art have many examples of changes to the original, wellknown type of cultural codes that broadcast information accumulated in culture in the form of signs and symbols. Decoding the content of a work of art or its simulation consists in the successive detection of cultural codes. Often these 
codes are combined or parodied in Intertext with ambiguity of interpretation and simultaneous appeal to different layers of the audience (Roland Barth, Jacques Derrida, Umberto Eco).

Cultural code, as a multivalued phenomenon, is devoted to works from different fields of science and technology - computer science, semiotics, philosophy, history, aesthetics, and cultural studies. Applying it in art criticism indicates the universalization and actualization of the content of the concept. It unites various levels of definition - a cultural code as a historically established structure and as a process of semiotic and semantic identification of meanings and forms of works of art.

In the works of postmodernism and post-postmodernism, "double coding” is akin to their specific art of deciphering codes in unusual comparisons, manifestation of semiotics and semantics of images, the psychology of their perception. It turned out that "double encoding" can be a substitute for interpretation. And this concerns not only works of postmodernism, but the whole history of art: select a code or several codes in images, form, content and find their new meaning, in fact - their interpretation.

The most famous cultural codes were mythological images and narratives, folklore and religious themes, plots, and heroes. On the basis of a consistent examination of these codes, it becomes possible to identify their new incarnation, often this is their transformation, which is the basis of "double coding". This happens through the inclusion of well-known quotations in the new text, which create allusions and reminiscences.

In these cases, codes, it can be code scenes, images, actions, reminiscent of signs. Citations, allusions and reminiscences can be considered as characters with different meanings. The main condition for signs and symbols is to be familiar data. In order to evaluate the work of mobile communication, you need to know the code as a necessary condition. Also in art to create the process of "double coding" the necessary condition is that the code is known to everyone: the author, recipients, performers.

Study of works of art made to analyze material in accordance with the era in the resulting work. Further, the means of expression, which reveal the artistic image in the work, are analyzed. However, it turned out that the works of contemporary art are easier to fix with known codes, which are transformed with each hit in a new context.

Based on the study of scientists about the "duality" of codes (Charles Sanders Peirce, Ferdinand de Saussure, Julia Kristeva, Jacques-Marie-Emile Lacan, Paul-Michel Foucault), among the cultural codes, "universal code", "code sign”, “code-language”, “code-symbol”, “code-genre”, “code-plot”, “code-plan”. But it turned out that regardless of their focus on genre, plot, etc., all culture codes have a historically established structure that conveys information at the first level 
of their recognition. At the second level, a process of semiotic-semantic establishment of additional meanings and forms of well-known cultural codes is already underway.

In the art of postmodernism, this process is called "double coding". Analyzing the works of postmodernism, it is easier to establish the meaning of culture codes in a new context, which sometimes coincides with their interpretation, and sometimes goes beyond just interpretation, as a change in some original source. For example, the specificity of codes in musical, visual, choreographic art, their genres, stylistic structure, intonation-rhythmic and signshaped spheres was found through the concepts of "episteme", "discourse", "discursive practice", "discursive events", "archives” (M. Foucault); "Semiotic structures" (Roman Jakobson and U. Eco); "Labels, labyrinths” (U. Eco); "Phonology - language" (Prague linguistic circle, Czech Semiotic School, Jan Mukarzhovsky); "Myth” (Claude Levi-Strauss); "Intonation” (Boris Asafiev); "Communicative archetypes, music labels" (Dina Kirnarskaya). In addition, the concepts of structural psychoanalysis about the functioning of a natural language-code in the form of metaphor and metonymy with the ability to transfer the name from one objects (phenomena, signs, etc.) to others on the basis of similarity or adjacent connection between objects acquire particular importance.

Such a process forms the conditions for ambiguous decoding of information with real, imaginary, symbolic codes (J. Lacan). Cultural code, passing through various practices, has the ability to provide artistic works with a worldview-cultural unity, forming a Ponadtexte organization of meanings, "associative fields” (R. Barth), intertextuality (J. Kristeva), "double coding” in art.

After the works of postmodernism were examined, it turned out that the history of art is filled with examples of the use of cultural codes from myths, folklore and religious motifs in the process of "double coding" in art as the invention of additional values and forms.

Since "double coding" in art is a complex creative process, its analysis requires a search for specific artistic techniques in which it occurs. Accounting for citation techniques, allusions, reminiscences, connotations, and contaminations helps to reveal the nature of "double coding" in its basic concepts and artisticfigurative "mechanisms". 


\section{Citation as a "double coding" technique in art}

Citing as an artistic technique of "double coding" quite often becomes the basis of a new compositional structure. The very concept of "quote" comes from Latin (citata, citarus, citare), which means "set in motion, shake, move" and has the meaning "literal excerpt from any text" $[1$, p. 773]. Already from this definition, we can conclude that citations in various types of art differ in their specifics. Therefore, in any form of art, the quotation or quoted material is concise, recognizable part of the previously created and resembles the semantic "code" with its informative fullness. Like the code, the quotation under certain conditions is a "communication model" (R. Jacobson).

Such an approach can be traced by the example of works by different authors. Composers use themes that become the codes of the author's text or write their work in the style of a famous composer. The leader of musical quotation can be called Wolfgang Amadeus Mozart. The writing of Petr Tchaikovsky "Mozartiana" contributed to the appearance of a number of similar works in the twentieth century: "Chopiniana" by Aleksandr Glazunov, "Scarlattiana" and "Paganiniana" by Alfredo Casella, "Vivaldiana" by Francesco Malipiero, "Telemanniana” by Hans Werner Henze as well as the ballets of Stravinsky Pulcinella, Kiss of the Fairies and other works ${ }^{2}$ [2].

Songs, dances and ceremonial actions of folk art have always been and continue to be such a form of "intertextual" communication. Almost code words of the Russian composer Mikhail Glinka, that "the people create music, and we, the composers, only arrange it”, are key for various examples of artistic creativity. A striking embodiment of M. Glinka was his overture "Kamarinskaya", in which he uses thematic musical quotation in the form of double variations. The composer relies on two folk melodies: the long Russian folk song "Oh, from the mountains, high mountains" and the dance "Kamarinskaya". Following the words of the song, the composer first conducts one theme, adding new echoes at each repetition, and then the second theme on the same principle. Finding the hidden possibilities inherent in these folk songs, becomes the basis for "double encoding" from the quotations of musical folklore. With this, this also applies to the title of the work - Kamarinskaya, since it is a folk dance.

This quotation concerns not only folk music, but also famous melodies that were included in the church masses of the Renaissance. For example, the Franco-Flemish composer, one of the pioneers of the Dutch school of Dufay,

${ }^{1}$ Dubicinsky, V. V. (2007). Modern Dictionary of Ukrainian language: 60000 words. Kharkiv: VD "School”. P. 773.

${ }^{2}$ Rogozhnikova, V. S. Mozart in the Mirror of Time: Text in Text: On the Problem of Interpretation of "Another's Word" in Music. Candidate's thesis. Moscow: Moscow State Conservatory. P. I. Tchaikovsky. 
always used the melody well known to all parishioners so that they could recognize it in the polyphonic work as well. Interestingly, motets also had code lines called "incipits" (the first words of the text or parts of it that are quoted when the work has no name or when several works have the same name). For example, Dufay's motets were known for special events and had code-incipits: for the consecration of the cathedral in Florence "Nuper rosarum flores" ("Recently rose flowers") or for the wedding of Malatesta - "Vasilissa ergo gaude" ("So rejoice, Princess").

The music of the Dutch composer Zoskena Despre received wide recognition as a result of the inclusion of an Italian folk song (frottelet) with a fast tempo and dance rhythms in a moderately emotional church music.

It is not by chance that even later the process of incorporating codes into a new text of a material used earlier becomes “double coding”. For example, Claudio Monteverdi, at the level of quotations and allusions, contains fragments of his own works in the opera "The Litany of the Virgin Mary" on modified tokkata (intraday) in the first prayer number "Domine ad adiuvandum" from "Orpheus". The composer does not change the theme of toccata, only adds a choral sound, enriching it with sonoric effects. Motet "Nigra sum" is also a recitative material of operatic monody in the style of recitative from the same "Orpheus". Another mote "Pulchra es" is like a chamber duo of the madrigal. Alyuziniy observed also in the performance of the echo effect, which was characteristic of church music. Thus, in the Audi, coelum, the composer addresses the traditions of Florentine interludes. "Duo Seraphim" from the allusion hints more at the virtuosity and pomp of the ornamental style of the instrumental piece of the time ${ }^{3}$ [3, p. 256].

Conditions for "double coding" are also created by the interaction of the ancient layers of culture and the modern language, the new context, which reflect the main cultural and historical transformations. For example, the appeal of domestic composers to the Ukrainian folk song has always been and remains natural. The unification of folk songs into cyclical works according to the principle of suite was a typical phenomenon of Ukrainian music in the second half of the XIX and early XX centuries. This tradition was started by Nikolay Lysenko with his "wreaths" of spring creepers; she was picked up by Fedor Kolessa ("The Street”), Kirillo Stetsenko ("Carols and Generos”) and other melodies of round-dance songs in the form of quotations are found in new texts, in Nikolay Lysenko's children's opera Winter and Spring (1892) or in Mihail Verikovsky's ballet music Mr. Kanevsky (1930). Citation of round dance melodies also occurs in the genre of symphonic music: in Lev, Symphony No. 2 (1927), Mihail Verikovsky, Vesnyanka (1924), Andrey Shtogarenko, In

\footnotetext{
${ }^{3}$ Konen, V. (1971). Claudio Monteverdi. Moscow: Soviet composer. P. 256.
} 
Memory of Lesia Ukrainka (1951). Round dance codes intonations and rhythms permeated suite Vladimir Nakhabin "Collective farm holiday" (1951).

Another kind of creation of conditions for "double coding” is an indirect, adapted quotation, for example, as in "Piano suites in the form of ancient dances based on folk songs" (1867-1869) by Nikolay Lysenko. An adapted quotation is "the translation of someone else's musical text with your own musical language", "the free development of someone else's material in your own manner" (Alfred Schnittke). Each miniature of the cycle Nikolay Lysenko has two names. The first one is the name of the number of the dance suite, known from the XVI century. The second name is the name of the song, on the basis of which the development of the whole part unfolds. So, 1.1. Prelude "Well done fellow, that you are lazy"; 1.2. Courant - "Little by little, brother, play"; 1.3. Toccata - "I went to the mother of the village"; 1.4. "The sun is low"; 1.5. Gavot - "Oh, whose girl are you, whose are you?”; 1.6. Scherzo "Yes, Solokha told me." Here Lysenko's intonational development of folk songs is combined with polyphonic development. The exception is Sarabande, where the composer uses the song Sun-Low. N. Lysenko builds his cycle on the principle of alternating non-dance and dance music, major and minor sections. The genre of the suite is characterized by a pictorial image and a close relationship with song and dance. Lysenko combines dance (chiming clock, gavotte, saraband) and folk songs.

Nikolay Lysenko likes certain folk songs so much that he uses them repeatedly in his works. For example, the composer uses the melody of the song "Well done boy, but you are lazy" (Prelude) in the "Fantasies for Two Ukrainian Folk Themes" for violin (or flute) with piano and in Peter's aria in the third act of the opera Natalka Poltavka.

The literal quotation of folklore occurs infrequently, but in the ballet "The Fable of the Fox, Kota da Baran" Igor Stravinsky refers to Russian folk texts. The genre of "fun performance with singing and music" determined by the composer fully corresponds to this. In addition, this genre is associated with the traditions of buffoons and a booth. The main character, the Fox, quotes folk poetry, and there are many folk songs in the musical text. For example, the dance of the Rooster, Kota and Baran based on folk dance songs. The bright song of Kota and Baran "Package, bale, guseltsi” has a folk basis. More archaic intonations - in the second dance of the Rooster, Kota and Baran. In general, "Bike" resembles a popular ballet performance with dancers, vocal quartet and orchestra of the original composition. The peasant orchestra is represented by string and wooden wind instruments one by one, and the percussion instruments are numerous. Even exotic Hungarian cymbals are included in the orchestra. I remember the "Ukrainian Requiem" by Alexander Kozarenko using an incredible number of folk instruments in such a genre as a requiem. 
Therefore, quoting and combining various codes (Roland Barthes), including various folklore codes (musical, literary), creates the "basis of double coding” (Charles Jenks).

Any citation in art forms a figurative microsystem, which includes the ratio of the various uses of artistic material (music, literature, painting). In addition to folk quotation, the reproduction of mythological plots, names, and names in artistic works is quite common. At the same time, the philosophy of myth, in our opinion, includes its own structural logic of the code, its semiotics, poetics, aesthetics. For example, Jacob Golosovker, in addition to the historical component, highlights in the myth structural logic with inherent dynamics and dialectics. Analyzing the semiotic structure of the myth, he emphasizes that in its semiotic structure its "poetic form is dynamic. She is the subject of the poetics of myth. The dialectical content of myth is semantics" ${ }^{4}$ [4].

For example, Sergey Prokofiev in the Scythian Suite (1916) was influenced by the mythological images of Ali and Lollia. The summary of the ballet is as follows: the ancient Slavs worship good forces - the sun god Veles and wooden idol Ali. Their cunning enemy, Tuzbog, with the help of wild and evil monsters, wants to kidnap Alu, but the Scythian hero Lolly becomes his defense. In an unequal battle with Alien, he faces death, but at the crucial moment Veles appears and strikes Alien with his sizzling rays.

The musical quotation is quite complex and by the nature of its perception. After all, the tradition of "double coding" is also due to quoting fragments of other musical works, which are almost not mentioned in the new work, in contrast to literary or scientific publications. To recognize musical quotes you need to meet in the art of music and the history of musical culture. Of course, composers sometimes record quoting or any other borrowing in the title, program or dedication of a new work. For example, the theme of the nine variations of Beethoven was Marsh c-moll (1783) of opera singer Ernst Dressler. In general, Beethoven often turned to the variation genre: Six variations for piano on the theme "Nel cor piu non mi sento" from Paisiello's opera La Molinara in G major (1795) Twelve variations for piano on Russian dance from Pavel Vranitzky's ballet Das Waldmädchen in A major (1797) Eight variations for piano on the theme "Une fievre Brûlante" from the opera by Andre Ernest Modest Gretry "Richard the Lionheart" in C major (1798), Variations for piano on the theme "La stessa, la stessissima" from the opera by Antonio Salieri Falstaff in B Major (1799) and many others. Famous were the variations of Fryderyk Chopin on Mozart's La Ci darem la mano (aria from the opera Don Juan).

${ }^{4}$ Golosovker, I. E. (2010). The Logic of the Myth. Moscow: SPb: Center for Humanitarian Initiatives. 
Autocitation is associated with the fact that the composer consciously or subconsciously uses a musical code or some kind of common code-image in which timeless ideas are laid, and it is they who reveal artistic images. During his creative life Ludwig van Beethoven had an impartial fascination with ancient literature, which influenced the writing of his individual works. For example, in the ballet Creation of Prometheus (1801), the composer quotes a contradance written by him earlier. Then Beethoven quotes the same fragment in the Piano Variations (1802) and in the finale of the "Heroic" symphony (No. 3), which he first dedicates to Napoleon Bonaparte. After the disappointment of Napoleon's activities, Ludwig van Beethoven's symphony is dedicated to the "memory of a great man," most likely to mythological Prometheus.

The disclosure of additional features of well-known musical themes is one of the techniques of "double encoding". Sometimes such a quotation consists of a whole complex of quotations. This forms a new, complex story, within which there are semantic links with musical associations for dedication texts. For example, Variations on the French Folk Song (op. 10 for two pianos) Franz Schubert becomes such a dedication to Ludwig van Beethoven. From the biography of Beethoven we know what significance the antimonarchical France and the French revolution had for the formation of his civic position. Apparently, therefore, Franz Schubert used the French song for his variations. Why did Beethoven dedicate his variations to Schubert? Because Beethoven was for the young composer a certain pattern in music and civic position. Therefore, associative links (codes) refer the listeners' imagination to historical facts, creating conditions for "double coding" in art.

The function of enhancing the dramatic expressiveness is performed by quoting a fragment from the Bach choral in the violin concerto by Alban Berg. In addition, this quotation has another meaning, namely, the Concert dedicated to the early deceased daughter of friend A. Berg ${ }^{5}[5$, p. 358].

A musical quotation as a "double coding" technique can also create parody or comic effects. In this aspect, an example is the suite of CharlesCamille Saint-Saens "The Carnival of the Animals" (1886) with the borrowing of codes and their interpretation. In the play "Chickens and Roosters", the composer quoted the "chicken" motif from the harpsichord suite of François Couperin. His figurative incarnation of C. Saint-Saens. Quoting Cancan from the operetta of Offenbach "Orpheus in Hell” by Saint-Saens makes a comic effect. Since the cancan in the Turtle Room sounds in slow motion and is not perceived from the first listening. Turtles and cancan - this is already in itself original. A turtle who dances or simply moves in the rhythm of a vigorous

${ }^{5}$ Lissa, Z. (1970). Aesthetics of film music / trans. with him. A. Zelenina and D. Karavkina. Moscow: Art. P. 358. 
French dance is absurd. Finding a new sense of kankan, like a turtle dance, the simultaneous use of the symbol of slow motion and fast kankan became a "double coding" technique in this piece.

Almost the same as with the Turtles, the composer comes with the play "The Elephant" when the waltz melody from the dancing elephant is borrowed from the Sylphide dance (from Berlioz's Damnation of Faust) and Felix Mendelssohn's comedy The Midsummer Night's Dream. The melodies, in the original, are performed in a high register, in "Elephant" they barely move in a low register. Such connotation in transcoding creates the comic music, reveals a "double" reading of the original source and its reincarnation.

The original method, namely parody, becomes "double encoding" as the simultaneous operation of several semantic systems. For example, from the ratio of several texts, when the foreground of the text (the ancient myth, the traditional genre and social traditions) falls into the new conditions, forming a parody. A similar approach is demonstrated by the French composer, conductor, founder of the operetta genre - Jacques Offenbach in his opera Orpheus in Hell (1874).

In his other opera The Tales of Hoffmann (1881), Jacques Offenbach quotes a fragment of the introduction of Mozart's opera Don Juan. The actions of Offenbach's opera take place in Mr. Luther's crowded tavern in Nuremberg. Next to the pub in the theater, there is a performance of "Don Juan", and therefore quoting the introduction of Mozart's opera is a natural display of the events of the performance.

These two types of quotations in Offenbach have a multi-vector nature of "double coding": the first is a parody character with a new context, the second is a new context, but the text remains unchanged, however both quotes create conditions for the "double coding" of the work and the perception of the recipients.

Almost the same as in the music of Offenbach, the musical quotation is used in the opera "The Queen of Spades" by Petr Tchaikovsky (1890) in the scene where the old countess sings an aria from the comic opera of the French composer Andre Gretrie "Richard the Lionheart" (1784). This aria symbolizes the memories of the countess of her youth, and for the listener knowledgeable in the history of music, the corresponding cultural and historical context. The citation of the theme of love from Tchaikovsky's Symphony No. 6 in the British film "The Ruling Class" (1972, England, director Peter Medak) is organic, as it happens in the love scene. In general, the film itself is an adaptation of the satirical play by Peter Barnes, which is also a "double coding" fact from the citation.

Quotes as "double encoding” techniques become symbols of time. For example, Dmitriy Shostakovich in the Soviet, and at that time the avant-garde cinema masterpiece "New Babylon" (1929) performs the original quotation of the music by J. Offenbach, which becomes musical symbolism. The authors of 
this black-and-white film (G. Kozintsev and L. Trauberg) refer to the historical and revolutionary events in France in the 1870s. The main heroine of the film, the saleswoman Louise, from the huge Parisian store New Babylon, comes to the barricades of the Paris Commune, and her lover, soldier Jean, changes herself and becomes a punitive. The whole film is permeated with reminiscences on the events of the 19th century French revolution and culture, as well as on the literature of Victor Hugo, Emile Zola, impressionistic painting and the traditions of Manet, Degas, Pissarro.

The controversy is the release of this movie with a tragic outcome in the 1920s of the Soviet "victorious" time. But the music for the film by Dmitriy Shostakovich, by that time already a venerable composer, is organic. Even when quoting fragments from the opera by Offenbach, the cancan from Orpheus in Hell and Marseillaise. The composer spends these two quotations in a contrapuntal combination. Their symbolism points to the contradictions in life between the philistine ideology and the revolutionary attempts that are contained in the film. Therefore, here quotes play the role of historical and cultural symbols or become "double coding" of the audience.

In this context, the desire of Soviet composers to convey in their music the "pulse of time" with the help of codes is also mentioned. This is also associated with quoting as a "double coding" technique. For example, in "Symphony No. 16" (1935-1936) Nikolay Myaskovsky uses the massive song of the time "Planes are flying", which was dedicated to the heroic military aviation. The song becomes a time code in the form of a semiotic structure, conveys information about the Soviet military period on the basis of incorporating it into a new context.

The quotation as a transmission of the spirit of the time, namely, the essence of the classic provisions of the aesthetics of Boileau and his Art Poetique, works by Descartes and Pascal, takes place in the Apollo Musaget (1928) ballet by Igor Stravinsky. Once in the new context, the text of "Poetic Art" by the French poet Bualo only emphasized the peculiarities of the classicism of the era of Louis XIV, to which the poet and then Stravinsky turned first. Having received a push from Boileau, the composer created a strict and laconic score of "musical Alexandrian poems" with their rhythms and meter of the 17th century. "The pizzicato accompaniment in one of the variations also arises, he said, from the Russian Alexandrian verse, suggested to him by the stanza of Pushkin"6 [6].

Therefore, quoting this code "fate or question" has a complex system of application. On the one hand, a certain figurative meaning was attached to it,

${ }^{6}$ Homans D. (2001). Excursion into the history of the creation of the ballet Apollo Musaget. Retrieved from: http: //www.bolshoi.ru/performances/571/details/. 
and on the other hand, a new image emerged on the basis of a solid foundation, which contributes to "double coding". After all, "if you have to talk about the specifics of a musical language, then it can manifest itself in two ways: not only in the way music speaks (the specifics of the display method), but also in what the music says (the specifics of the information itself). In different eras, this problem was solved in different ways" ${ }^{7}$ [7]. Also, this characteristic of the musical language coincides with the ratios of the indicated and designated, the language-broadcasting of the concept of Ferdinand de Saussure.

Another musicologist, Andrey Kudryashov, considers such a quote by Shostakovich as a peculiar synthesis of musical and vocabulary intonation. In his opinion, this synthesis enhances the vocalism of melodic thinking in instrumental genres. The function of the verbal explanation in Shostakovich's Symphony No. 15 is also performed by direct quotations by Giovacchino Rossini and Richard Wagner ${ }^{8}$ [8, p. 201].

Thematic autociting as one of the "double coding" techniques in art makes P. Tchaikovsky in the second part of his First Symphony, introducing into the text a theme from his youthful overture "The Thunderstorm". Later, the composer uses this theme in his music for the spring fairy tale of Aleksandr Ostrovsky "The Snow Maiden”. In the third part of the same symphony (No. 1), Tchaikovsky also used the theme from his piano sonata in C-sharp minor. Therefore, autocitats become theme codes with a specific system of previously found intonations, rhythmic formulas and other means of musical expressiveness.

Autocitation as a cultural code in music and the method of "double coding" in art is found in Sergey Rachmaninov in the code and parts of his "Symphonic Dances" with a quote from the main part and part of his symphony. Phenomena of such quotation, which are turned not only into the past of the author, but also into the future work, probably reflect the ideological experiences of artists or the common thoughts that they themselves had previously embodied in their work. That is, the once successfully found topic is again used in the new context.

The phenomenon of citation as a technique of "double coding" in painting coincides with the programmatic character that influences the structure of the image. For example, Rafael Santi in The Betrothal of the Virgin Mary (1504) used the composition scheme of his teacher Pietro Perugino's The Betrothal of Mary (1500-1504). Although distinguish these two pictures can only specialists. Both pictures have almost the same background, actors. But each author in his own way emphasized textural means.

\footnotetext{
${ }^{7}$ Bonfeld, M. (1991). Music. Tongue. Speech Thinking. Moscow: Music.

${ }^{8}$ Kudryashov A. Yu. (2006). Theory of musical content. Artistic ideas of European music of the XVII - XX centuries: studies. allowance. St. Petersburg: Lan. P. 201
} 
In particular, Raphael's “Engagement” with his elusive sense of space, with grace and even some refinement, highlights such coloristic aromas and freshness that Perugino's fresco does not know. When you look at the picture of young Raphael, you are covered with anxious and exciting feeling, as if early in the morning, when the air is cool and clean, you were suddenly transferred to a beautiful country, where unusual and attractive people made a beautiful and elegant holiday. The distant outlines of mountains and hills stretching to the very horizon form the background of this picture" ${ }^{\text {[9] }}$.

As for Perugino, his picture is built on contrasts and symmetry. Strict straight lines are combined with rounded shapes, but the characters look alive and natural. Gentle colors and excellent reproduction of every detail makes the picture the personification of the divine power that lives on Earth in everything $^{10}[10]$.

The picture of Salvador Dali "A paranoid and critical analysis of the work of Jan Vermeer "Lacemaker" (1955) can be viewed at an angle of "double coding" with quoting. Salvador Dali rethinks textural, timbre and dynamic means, mainly emphasizing the contours of the image, and creates a stylistic contrast to the original source, as well as conditions for the process of establishing semantic links and decoding the content of the new work.

\section{Citations and allusions as codes in "double coding" in art}

Citation contributes to the multivariate reading of the text (Eco). Therefore, it is not accidental in music that there is a citation of one melody by different authors in the characterization of one image, but with different decoding. For example, the chorus "Oh, how the sun glories in the sky to the red," is well known from Aleksander Borodin's opera Prince Igor. In addition, he sounds in the scene of the coronation of Tsar Boris in Modest Mussorgsky's opera Boris Godunov, Prologue, the second picture. In Nikolay RimskyKorsakov in the opera Tsar's Bride, the melody of the choir appears in the scene of Tsar Ivan the Terrible with Martha. This short meeting is a turning point in the development of drama, and the composer emphasizes the significance of this scene by purely symphonic means: the melody of Glory sounds solemnly, strictly and ominously in the orchestra, one of the themes of Grozny. In Shostakovich, this topic acquires an open grotesque. And Ludvig van Beethoven quotes "As the sun is in the sky, the red glory!" Becomes the theme of the fugue for the "Russian" quartet "Razumovsky", which was commissioned by Andrey Razumovsky as one of the three "Russian" quartets (1806-1807). This theme is cited in the Symphony No. 27 by Nikolay Myaskovsky (1947).

\footnotetext{
${ }^{9}$ Ryzhko, V. A. (2000). Universal Measurements of Ukrainian Culture. Odessa: Print.

${ }^{10}$ Strada, P. (2012). Sandrine Bandera Pinakothek Brera. Geneva-Milan: Skira.
} 
Composers' endless interest in quotations in compositional construction is sometimes connected with the fact that a melody found once has a "hypnotic effect" on listeners. This happened to the Bolero of the French composer, conductor, one of the reformers of the music of the 20th century Maurice Ravel. Without recounting the many ballet performances to this music, let us recall the election of this music by the composer Alfred Schnittke in constructing Woland's ball in the film version of the novel The Master and Margarita (1994). Another example is the quotation of "Bolero" directed by Jean-Luc Godard as a sound and rhythmic layer for his short film "Letter to Freddie Buchach" (1982). In the film, Godard himself turns on the record on the record, and the video sequence is built on the rhythm of the work and is accompanied by the reading of letters (the director's voice sounds off-screen).

The problems of creativity, starting from the twentieth century, also encountered the concept of editing, which was developed by Sergey Eisenstein. In his article "Montage of Attractions" (1923) it is stated that "collages from quotations similar to cento from other people's poems mentioned by Bakhtin, became half-common in modern art prose, where quotations can be viewed as metonymically substitutes for the whole text. Thus, they are included in the metonymic system of prose narrative works" ${ }^{11}$ [11, p. 19-20]. In addition, as noted Vyach. Ivanov on Eisenstein's attitude to the post-cubistic function of quotations in collages, "a composition from quotations can be used to create a whole treatise" ${ }^{12}[11]$.

Citation as an artistic technique of "double coding" in art is predominantly associated with texts that unfold over time and have the nature of a linear organization as opposed to texts of a spatial organization (architecture, sculpture, painting), which by their nature are less prone to using quotes.

Musical quotation, despite the fact that it is impossible, as in a written text, to put quotes, is replete with borrowings at the level of intonations, codes, time codes, cultural and historical context. As in verbal speech with its symbolic nature, so in music, quotation affects the structural orderliness of the text, recalls "a communicative conference with alternating phrases and blocks of events" (U. Eco). Both in music and in other types of art, in the title of a new work, dedication can be noted to the author, whose text is cited.

Citation in painting is akin to the inclusion of well-known images in the new context of the era, style, image. In choreographic art, quotations are found at the level of plots, musical design, figurative interpretation of well-known

${ }^{11}$ Ivanov, V. V. (1973). The value of Bakhtin's ideas on the sign, utterance and dialogue for modern semiotics. Scientific notes of Tartu State University. Works on landmark systems VI, 308, pp. 19-20 .

${ }^{12}$ At the same place. P. 20/ 
plastic codes. Therefore, the quotation in "double coding" in art appears in two ways - by the cultural code itself or its attendant additional value.

"Double coding" in art as a process of gradual encryption of information or the invention of additional values of a cultural code coincides with the use of the imaginative system of artistic means and techniques, among which the main place is taken by the allusion. Allusion (Latin Allusio - hint, joke) contains an indication or analogy of a certain historical, mythological, literary, political or everyday fact, fixed in a text culture or in colloquial speech ${ }^{13}[1$, p. 26].

In the visual arts, which borrows individual elements of myths, creating semantic-compositional structures of new works, mythological names and events of myths are often beaten up. For example, the name and content of the myth about Apollo, which in the history of artistic culture became the sign-code of classical art, is used in paintings and plastics, starting with antiquity. His beautiful image was conveyed in the exterior of the famous marble statue of Apollo Belvedere. All artists often tried to portray the chase of Apollo for Daphne. "Running the divine patron of the arts over five centuries is a funny and instructive spectacle" ${ }^{14}[12]$. The allusion, consistent with the Apollo code, has become a cultural cliche with the meaning of "beauty".

In addition, the embodiment of the Apollo laurel code, as an allusion to the inaccessibility of beauty, transmitted in the painting "Apollo and Daphne" by Florentine painter, sculptor, jeweler and engraver Antonio del Pollayolo (XV century). Patron of the arts Apollo in the then elegant golden coat with bare legs overtakes a girl with disheveled hair. Throughout the whole scene, there is a special, even crony, attitude of the Florentine Quattrocento to antiquity, although the scene of the picture conveys the events of that time on the streets of Florence. The symbolic laurel arms of Daphne remind us that the scene is an allusion or embodiment of the myth according to Ovid's Metamorphosis. For Florence $\mathrm{XV}$ century. there was a certain balance between paganism and Christianity, antiquity and modernity, which was formed in the philosophy of Neo-Platonism and in the aesthetics of the Renaissance. She gave a happy opportunity to make gods with her contemporaries, and contemporaries with gods ${ }^{15}[12]$.

This interpretation of the image of Apollo resembles the interpretation of the Sophists and the Stoics, according to which the code and coding in the myth can be seen on the example of the personification of the gods. According to Plato, we observe the philosophical and symbolic interpretation of this myth. Also, the Hellenistic philosopher Eugemer saw deified historical figures in

${ }^{13}$ Dubicinsky V. V. (2007). Modern Dictionary of Ukrainian language: 60000 words. Kharkiv: VD "School”. P. 26.

${ }^{14}$ Ippolitov A. (2008). Apollo and Daphne. Retrieved from: http://www.renesans.ru/ anthology/06.shtml.

${ }^{15}$ Ibid. 
mythical images, and it is not surprising that in some countries this approach continues to this day, which is why it is possible to use such acquaintances for all codes. Actually allusions in combination with this code-image, already as independent artistic constructions, have a deeper interpretation than just a mythological image. From the point of view of psychology, it is known that the exact wording is not preserved in a natural way. But it can be recalled, paying attention to the general information, that is, the meaning is coded better than the stylistic information.

In contrast to the ancient Greek interpretation of mythological codeimages, during the Middle Ages, Christian theologians identified ancient gods with demons. Renaissance humanists interpreted ancient mythology as moral and poetic allegories, while a purely allegorical interpretation of myths remained before the Boccaccio treatises and the philosophical works of Frensis Bacon. This is noted in the code-images of Apollo and Daphne in the engraving “Apollo and Daphne” by the Italian master Agostino Veneciano (16th century). The artistic reception of the allusion here is a dialogue of the Masters with their predecessors and contemporaries. So, in the code-image of the face of Apollo Musaget Veneciano used Baccio Bandinelli's drawing. He has on his engraving the face of Apollo sends the intellectual perceptual to the image of B. Bandinelli known at that time. Apollo and Daphne are naked, as befits the ancient deities, that is, Ag. Veneziano in allusions conveyed the atmosphere of that time.

Allusion to the code-image of Apollo in the image of Agostino Veneciano is related to the use of a mythological name. Because the very transmission of the movement of Apollo was characteristic of the XVI century. The artist conveyed the divine run of Apollo with the help of a symbolic cloud under his foot. We will learn about Daphne by her hand, which has turned into a branch of a tree, which over time has also become a code. Therefore, allusions to the myth of Apollo with the symbol-cloud, as a reflection of the movement of Apollo, resemble the Lacanian concept of the structure of the myth. In it, the scientist examines the ratio of codes of the real, the imaginary and the symbolic, which, in a projection on the myth, synthesize the past and the modern. In this concept, "It" takes the real, the role of "I" performs the imaginary, the function of "super-I" is symbolic, which in the conscious and subconscious creates conditions for the emergence of artistic images. These real, imaginary and symbolic images further influence the process of encoding and decoding (real, imaginary and symbolic codes). Real images of engraving Agostino Veneciano - Apollo and Daphne. Imaginary images arise in the process when Apollo catches up with Daphne, and the nymph turns into a tree. The symbolic beginning is reflected in the appearance of the Laurel symbol. Apollo appears here as the winner of unattainable beauty, makes Daphne Laurus with her sacred symbol-code-tree, 
and the first crowns herself with a laurel wreath. In this example, the allusion serves as a reference to a well-known myth led by the Olympic god. At the same time, it complicates and facilitates the perception of both the text as a whole and well-known cultural codes, showing hidden meanings, that is, becoming a technique of "double encoding" and decoding.

The illusions of Apollo Belvedere (from the drawing of Baccio Bandinelli) also appear in the Apollo and Daphne sculpture (1622-1625) by the Italian sculptor and architect Lorenzo Bernini (1598-1680), who is considered an exemplary master of the dynamics of baroque forms. And in this sculpture, he freely conveys movement, going beyond the limits of baroque dynamics, causes associations with the images of the movement of spatial abstract compositions already in the 20th century. In his sculpture Lorenzo Bernini captured the moment of the mythical chase of the sun god behind the nymph Daphne. Nymph appeals to the gods for help. Her fingers turned into branches, her legs became the roots of the laurel, evoking the corresponding associations in the imagination of the audience. The future Pope Urban VIII wrote instructive lines that everyone who would seek pleasure in vanishing beauty would wake up with his hands full of leaves and bitter berries ${ }^{16}$ [13, p. 22-23].

The content of the myth in this case coincides with the poetic form of information storage of the image codes of Apollo and Daphne and those moral truths that are encoded in the form of symbols, allegories and allusions to these images.

Venetian painter, draftsman and engraver Giovanni Battista Tiepolo widely used allusions to the mythological codes in the Rococo style. His works on mythological subjects by means of the visual arts represent the triad "mythcode-information". The codes-images of his works, referring the imagination to the original sources, evoke stable associations. For example, the painting "The Triumph of Aurora” (1719-1720) depicts mythological and allegorical characters, which have in common a picture with a theatrical act. In addition, the viewer's eye is affected by a large amount of golden-blue color, like an inner light. Such allusion color patches remind of the pictorial style of Piazzetta, although Tiepolo fundamentally departs from the dark color spectrum that was characteristic of Piazzetta. He imitates the baroque style of Lazzarini, the personal style of Sebastiano Ricci, which indicates the search for his own style at the beginning of his creative career, in the first half of the 18th century.

${ }^{16}$ Serres, M. (1977). La Naissance de la physique dans le texte de Lucrece: Fleuves et turbulences. 


\section{CONCLUSIONS}

Based on the analysis of works of art, the reasonably semiotic, semantic and text-organizing nature of citation, which involves the levels of style, themes and compositional structure of the artistic image and represents the artistic techniques of "double coding" in the transformation of the original source. Differentiated various types of citation codes (style, genre, theme, image, structure) with the identification of aesthetic communicative function (parodies, comedy, irony), semantic constructions of new and well-known materials with consistent decoding of cultural codes in art history. The citation is related to an allusion or reminiscence of mythological, folkloric, sacral codes. Even if the initial content changes and new connotations and contaminations are obtained, culture codes are necessarily recognizable.

The semiotic function is inherent in the nature of the allusion, which helps produce the semantics of the updated cultural code in a new context. The text-forming and semantic functions of allusions form the ambivalence of compositional structures in new works. Semiotics of contamination was found in the interspersing of one text into another with the creation of a new semantic field.

Allusions, reminiscences, contaminations in playing around mythological, folklore, sacral codes are defined as textual formation, constructing a recipient thesaurus for an adequate perception of the semantics of works.

\section{SUMMARY}

The article discusses the problems of "double coding" in the history of art. On the example of literary works, the characteristic features of "double coding" are revealed.The purpose of the article is to highlight the codes of culture and the methods of "double coding" in works of art from different historical periods. The work methodology is based on the use of comparison methods; generalizations for the conceptualization and expansion of the meaning of "cultural codes" and "double coding" in art. The scientific novelty of the work lies in the actualization of the questions of "double coding" in art as a process of finding new meanings and forms of works.

\section{REFERENCES}

1. Dubicinsky V. V. (2007). Modern Dictionary of Ukrainian language: 60000 words. Kharkiv: VD "School” (in Ukrainian).

2. Rogozhnikova V. S. Mozart in the Mirror of Time: Text in Text: On the Problem of Interpretation of "Another's Word" in Music. Candidate's thesis. Moscow: Moscow State Conservatory. P. I. Tchaikovsky (in Russian).

3. Konen V. (1971). Claudio Monteverdi. Moscow: Soviet composer (in Russian). 
4. Golosovker I. E. (2010). The Logic of the Myth. Moscow: SPb: Center for Humanitarian Initiatives (in Russian).

5. Lissa Z. (1970). Aesthetics of film music / trans. with him. A. Zelenina and D. Karavkina. Moscow: Art (in Russian).

6. Homans D. (2001). Excursion into the history of the creation of the ballet Apollo Musaget. Retrieved from: http://www.bolshoi.ru/performances/ 571/details/ (in Russian).

7. Bonfeld M. (1991). Music. Tongue. Speech Thinking. Moscow: Music (in Russian).

8. Kudryashov A. Yu. (2006). Theory of musical content. Artistic ideas of European music of the XVII - XX centuries: studies. allowance. St. Petersburg: Lan (in Russian).

9. Ryzhko V.A. (2000). Universal Measurements of Ukrainian Culture. Odessa: Print [in Ukrainian].

10. Strada, P. (2012). Sandrine Bandera Pinakothek Brera. GenevaMilan: Skira (in English).

11. Ivanov V. V. (1973). The value of Bakhtin's ideas on the sign, utterance and dialogue for modern semiotics. Scientific notes of Tartu State University. Works on landmark systems VI, 308, 5-44 (in Russian).

12. Ippolitov A. (2008). Apollo and Daphne. Retrieved from: http://www.renesans.ru/anthology/06.shtml (in Russian).

13. Serres M. (1977). La Naissance de la physique dans le texte de Lucrece: Fleuves et turbulences (in English).

\section{Information about the author:} Afonina O. S., orcid.org/0000-0003-1627-6362 Doctor in Art Studies, Prof. of National Academy of Culture and Arts Management 9, Lavrska str., 03179, Kyiv, Ukraine 